\title{
Synaptic boutons sizes are tuned to best fit their physiological performances
}

\author{
Markus M Knodel ${ }^{1,2 *}$, Dan Bucher ${ }^{2,3,4}$, Romina Geiger ${ }^{3}$, Lihao Ge ${ }^{3}$, Alfio Grillo ${ }^{1,5}$, Gabriel Wittum², \\ Christoph Schuster ${ }^{2,3}$, Gillian Queisser ${ }^{1,2}$ \\ From Twenty Second Annual Computational Neuroscience Meeting: CNS*2013 \\ Paris, France. 13-18 July 2013
}

To truly appreciate the myriad of events which relate synaptic function and vesicle dynamics, simulations should be done in a spatially realistic environment. This holds true in particular in order to explain as well the rather astonishing motor patterns which we observed within in vivo recordings which underlie peristaltic contractionsas well as the shape of the EPSPs at different forms of long-term stimulation, presented both here, at a well characterized synapse, the neuromuscular junction (NMJ) of the Drosophila larva (c.f. Figure 1). To this end, we have employed a reductionist approach and generated three dimensional models of single presynaptic boutons at the Drosophila larval NMJ. Vesicle dynamics are described by diffusion-like partial differential equations which are solved numerically on unstructured grids using the $\mathrm{uG}$ platform. In our model we varied parameters such as bouton-size, vesicle output probability (Po), stimulation frequency and number of synapses, to observe how altering these parameters effected bouton function. Hence we demonstrate that the morphologic and physiologic specialization maybe a convergent evolutionary adaptation to regulate the trade off between sustained, low output, and short term, high output, synaptic signals. There seems to be a biologically meaningful explanation

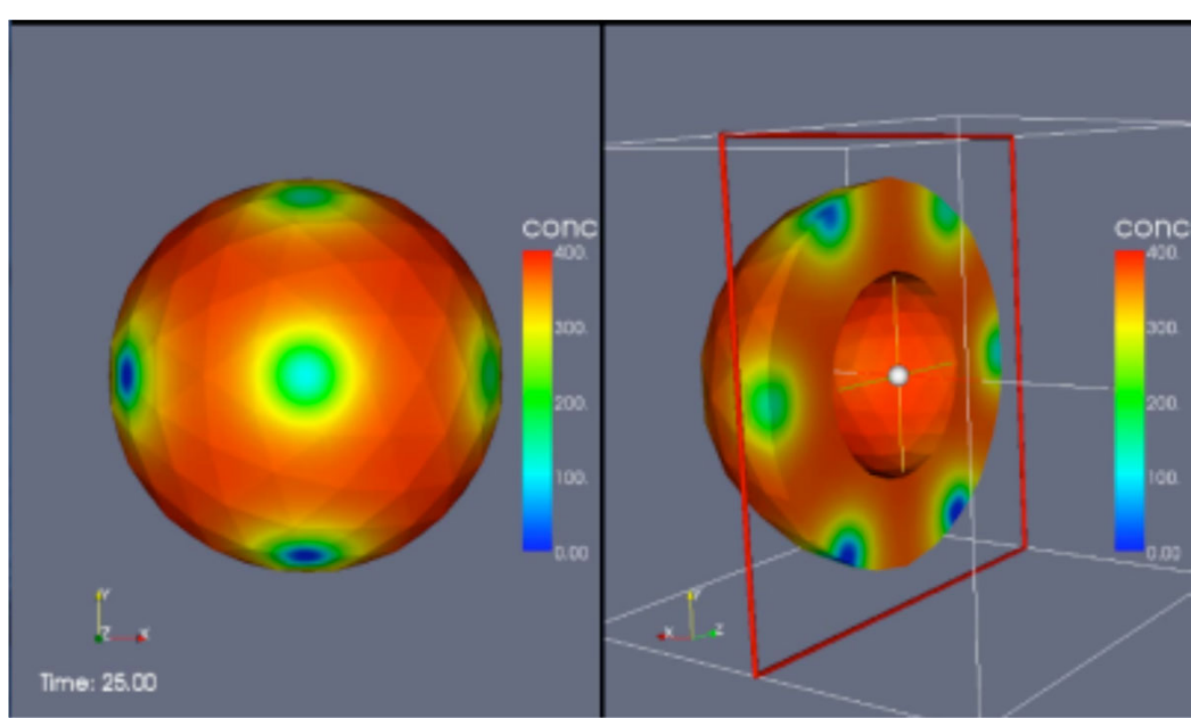

Figure 1 Simulation of a bouton of the Drosophila NMJ

\footnotetext{
* Correspondence: markus.knodel@gcsc.uni-frankfurt.de

'Goethe Center for Scientific Computing, Frankfurt University, Germany

Full list of author information is available at the end of the article
}

(c) 2013 Knodel et al; licensee BioMed Central Ltd. This is an Open Access article distributed under the terms of the Creative Commons 
for the co-existence of the two different bouton types as previously observed at the NMJ (characterized especially by the relation between size and Po), the assigning of two different tasks with respect to short- and long-time behaviour could allow for an optimized interplay of different synapse types. We can present astonishing similar results of experimental and simulation data which could be gained in particular without any data fitting, however based only on biophysical values which could be taken from different experimental results. As a side product, we demonstrate how advanced methods from numerical mathematics could help in future to resolve also other difficult experimental neurobiological issues.

\section{Author details}

${ }^{1}$ Goethe Center for Scientific Computing, Frankfurt University, Germany. ${ }^{2}$ Bernstein Group for Computational Neuroscience, Heidelberg University, Germany. ${ }^{3}$ Interdisciplinary Institute for Neuroscience, Heidelberg University, Germany. ${ }^{4}$ EMBL Heidelberg, Germany. ${ }^{5}$ Dept. of Mathematical Sciences, Polythecnic of Turin, Italy.

Published: 8 July 2013

\section{References}

1. Jan $L$, Jan $Y$ : Properties of the larval neuromuscular junction in Drosophila melanogaster. J Physiol 1976, 262(1):189-214.

2. Schuster C, Davis G, Fetter R, Goodman C: Genetic dissection of structural and functional components of synaptic plasticity. ii fasciclin ii controls presynaptic structural plasticity. Neuron 1996, 17(4):655-67, doi: 10.1016/ S0896-6273(00)80198-1.

3. Delgado R, Maureira C, Oliva C, Kidokoro Y, Labarca P: Size of vesicle pools, rates of mobilization, and recycling at neuromuscular synapses of a Drosophila mutant, shibire. Neuron 2000, 28:941-53, doi: 10.1016/S08966273(00)00165-3.

4. Bastian P, Birken K, Johannsen K, Lang S, Reichenberger V, Wieners C, Wittum G, Wrobel CA: In High performance computing in science and engineering. Springer;W. Jäger and E. Krause 1999:326-339, Parallel softwareplatform for solving problems of partial differential equations using unstructured gr ids and adaptive multigrid methods.

doi:10.1186/1471-2202-14-S1-P138

Cite this article as: Knodel et al:: Synaptic boutons sizes are tuned to best fit their physiological performances. BMC Neuroscience 201314 (Suppl 1):P138.

\section{Submit your next manuscript to BioMed Central and take full advantage of:}

- Convenient online submission

- Thorough peer review

- No space constraints or color figure charges

- Immediate publication on acceptance

- Inclusion in PubMed, CAS, Scopus and Google Scholar

- Research which is freely available for redistribution

Submit your manuscript at www.biomedcentral.com/submit
C Biomed Central 